Original Article

\title{
Behaviour specific cognition and affect for performing exercise among institutionalized elderly
}

\section{Rohisha I.K. ${ }^{1}$, Andrade M. ${ }^{2}$, Nayak B.S. ${ }^{3}$}

${ }^{1}$ Assistant Professor, Canossa College of Nursing, Kannur, KUHS, ${ }^{2}$ Assistant Professor, Department of Community Health Nursing, ${ }^{3}$ Professor, Department of Child Health Nursing, M anipal College of Nursing, M anipal, M anipal University.

*Corresponding Author : Rohisha I.K., IK House, Aingoth, Padannakkad PO, Nileshwar Via, Kasaragod Dist, Kerala,

E-mail : rohisharohu@gmail.com

Received

19.11 .2016

Review Completed : 12.01.2017

Accepted

:02.02.2017 elderly, behaviour specific cognition and affect, exercise

\begin{tabular}{|c|}
\hline Access this article online \\
\hline Quick Response Code \\
\hline
\end{tabular}

Keywords : institutionalized

\begin{abstract}
Exercise is proved to have physical, psychological, and social benefit on health. This study explores the perceptions of the elderly for performing exercise. The study aimed to enhance the quality of life of the institutionalized elderly. The outcome of the study can be utilized to plan and implement effective intervention to promote health of the elderly population. The objective of the study is to describe the behaviour specific cognition and affect (factors) for performing exercise among institutionalized elderly. The conceptual framework for the study is based on Pender's Health Promotion Model. The study was conducted in selected old age homes of Udupi and South Canara district $(n=29)$. Tool to assess the behaviour specific cognition and affect for the performance of exercise in old age was prepared by the researcher which include 33 items and was administered by self rated questionnaire. The analysis of the findings was done using descriptive statistics; frequency and percentage. Each item of the tool was analyzed separately using frequency and percentage. Majority of the participants found perceived benefit as it will improve mental health (93.1\%) and will reduce stress (86.2\%) and perceived barrier as difficulty to perform in old age (69\%) and lack of information (55.2\%). Perceived self-efficacy for performing exercise was feeling confidence (79.3\%), and self-worthy $(82.8 \%)$ to perform exercise. Activity related effect for performing exercise was that performing exercise will not make them sad. M otivation by the care givers $(93.1 \%)$ to perform exercise, lack of awareness of the benefits of exercise from media (65.5\%) were the interpersonal influences. Considering the situational influences $86.2 \%$ subjects felt the lack of facilities to perform exercise, 28 (96.6\%) subjects felt there was no supervisor or trainer for exercise. The study explored various perceptions of elderly on performing exercise. Based on the factors health professionals and caregivers can plan and modify the interventions. This will help the nurse to promote independence and sense of achievement among the elderly and these measures help the elderly in preserving and promoting function rather than contributing to a decline in their status.
\end{abstract}

\section{Introduction}

Old age is the final stage of life and is considered an adverse and despised period. In this later life most of the elderly are excluded from the modern society and are put into a solitary world. To be healthy in this later stage, a person has to function physically, psychologically, and socially. Exercise is proved to have physical, psychological, and social benefit on health. This study explores the perceptions of the elderly for performing exercise. The study aimed to enhance the quality of life of the institutionalized elderly. The outcome of the study can be utilized to plan and implement effective intervention to promote health of the elderly population. The objective of the study is to describe the behaviour specific cognition and affect (factors) for performing exercise among institutionalized elderly. Behaviour specific cognition and affect are the factors perceived by the elderly which affects their performance of exercise in terms of benefits, barriers, self-efficacy, activity related effect, interpersonal influences and situational influences which are assessed by a self-rated behaviour specific cognition and affect scale for the performance of exercise in old age. The conceptual framework for the study 
is based on Pender's Health Promotion M odel based on an idea that human beings are rational and will seek their advantage in health and viewed health promotion as increasing the client's level of well-being. Pender's model incorporates exercise as a healthcare reform among elderly to keep the responsibility of health on them.

\section{Materials and methods}

The study was conducted in selected old age homes of Udupi and South Canara district among 29 institutionalized elderly selected purposively. Self-administration of questionnaires was used to collect the data. The participants were requested to fill the questionnaires. Tool to assess the behaviour specific cognition and affect for the performance of exercise in old age was prepared by the researcher to assess the behaviour-specific cognition and affect for the performance of exercise in old age. The tool had sections with a total of 33 items, i.e., Perceived benefits ( 6 items), perceived barriers (10 items), perceived self-efficacy ( 5 items), activity related effect (4 items), interpersonal influences (5 items), and situational influences ( 3 items). Content validity and language validity was established. Pretesting was done and reliability of the tool was $r=0.91$. Self-administration of questionnaires was done to collect the data. Administrative permission was taken from Dean Manipal College of Nursing, Manipal, approval from the Institutional Ethics Committee, Kasturba Hospital, Manipal, the administrators of the geriatric homes and Informed consent was taken from the participants and confidentiality of the information was maintained to maintain the ethical aspects of the study. The analysis of the findings was done using descriptive statistics; frequency and percentage. Each item of the tool was analyzed separately using frequency and percentage.

\section{Results}

The findings of behaviour specific cognition and affect for performing exercise among institutionalized elderly are described under different concepts and represented in Table 1.

\section{Perceived benefits}

The data show that 27 of the subjects (89.7\%) agreed that performing exercise will make the body physically healthy and 27 (93.1\%) agreed that it will improve the mental health. M ost of the participants agreed that exercise will reduce stress $25(86.2 \%)$, provide good sleep at night $24(82.8 \%)$ and make them look better 23(79.3\%).

\section{Perceived barriers}

Most of the participants believed that performing exercise will not be a waste of time $26(89.7 \%), 12(41.4 \%)$ subjects believed that it will cause pain on body before exercise and 9(31\%) participants agreed that exercise will not bring any long term benefits. The information regarding exercise was lacking in 16 (55.2\%) participants, 20 (69\%) subjects believed that exercise is difficult to perform in old age due to loss of strength in old age and 12 (41.4\%) subjects agreed that exercise is a tough task. The interest in performing exercise was lacking in 10 (34.4\%) subjects and 12 (41.4\%) participants considered that self-conscious about the body stops from performing exercise.

\section{Perceived self-efficacy}

Most of the subjects felt confident to perform exercise $23(79.3 \%), 10$ (34.5\%) participants felt that they are fit to perform exercise, and 24 (82.8\%) subjects felt self-worthy to perform exercise. Majority 24(82.8\%) perceived that they can manage the time schedule and participate in exercise.

\section{Activity related effect}

Majority felt that performing exercise will make them happy 26(89.7\%), energetic 19(65.5\%), and daily life enjoyable $19(65.5 \%)$. All the participants $29(100 \%)$ felt that exercise will not make them sad.

\section{Interpersonal influences}

M ajority, 27(93.1\%) of the participants were motivated by the care givers to perform exercise, 18 (62.1\%) participants were influenced by the friends and were encouraged by seeing their friends performing exercise. Majority, $19(65.5 \%)$ of subjects were not aware of the benefits of exercise from media. M ost $24(82.8 \%)$ of them felt that they didn't want any company to perform exercise. 


\section{Situational influences}

Considering the situational influences, 25 (86.2\%) subjects felt the lack of facilities to perform exercise, 28 (96.6\%) subjects felt there was no supervisor or trainer for exercise and $12(41.4 \%)$ participants felt that somebody or something stops when they start doing exercise.

Table 1 : Percentage distribution of behaviour specific cognition and affect for performing exercise of institutionalized elderly

$n=29$

\begin{tabular}{|l|r|r|}
\hline Item & Yes & No \\
\hline PERCIEVED BENEFITS & & \\
\hline I feel performing exercise: & & \\
\hline Will make the body physically healthy & 89.7 & 10.3 \\
\hline Will improve mental health & 93.1 & 6.9 \\
\hline Will reduce stress & 86.2 & 13.8 \\
\hline Will maintain blood pressure in normal limits & 58.6 & 41.4 \\
\hline Provide good sleep at night & 82.8 & 17.2 \\
\hline Will make me look better & 79.3 & 20.7 \\
\hline PERCIEVED BARRIERS & & \\
\hline I believe performing exercise: & & \\
\hline Will has no effect on physical health & 3.4 & 96.5 \\
\hline Will be a waste of time & 10.3 & 89.7 \\
\hline Will cause pain on body & 41.4 & 58.6 \\
\hline Have no effect on mental health & 13.8 & 86.2 \\
\hline Will not bring any long term effects & 31.0 & 69 \\
\hline Is a very tough task & 41.4 & 58.6 \\
\hline Is difficult due to losS of strength in old age & 69.0 & 31 \\
\hline I lack information regarding the exercise & 55.2 & 44.8 \\
\hline Item & Yes & No \\
\hline I become self-conscious about my body which & & \\
\hline stops me from performing exercise & 41.4 & 58.6 \\
\hline I lack interest in performing this exercise & 34.4 & 65.5 \\
\hline PERCIEVED SELF EFFICACY & & \\
\hline I feel confident to perform exercise & 79.3 & 20.7 \\
\hline I feel I am fit to perform exercise & 34.5 & 65.5 \\
\hline I can manage my schedule and participate & & \\
\hline in exercise & 82.8 & 17.2 \\
\hline I feel self-worthy to perform exercise & 82.8 & 37.9 \\
\hline ACTIVITY RELATED AFFECT & & \\
\hline Performing exercise makes: & & \\
\hline me happy & & \\
\hline me sad & & \\
\hline me energetic & & \\
\hline me feel bored & & \\
\hline my daily life more enjoyable & & \\
\hline INTERPERSONAL INFLUENCES & & \\
\hline Care givers motivate me to perform exercise & 93.5 \\
\hline M y friends influence me to perform exercise & 62.5 \\
\hline I am aware of benefits of exercise from media & 34.5 \\
\hline I feel encouraged when I see my friends & \\
\hline performing exercise & & \\
\hline I need company to perform exercise & & \\
\hline
\end{tabular}

\begin{tabular}{|l|r|r|}
\hline Item & Yes & No \\
\hline SITUATIONAL INFLUENCES & & \\
\hline There are lack of facilities available to & & \\
\hline perform exercise & 86.2 & 13.8 \\
\hline Every time when I start exercise something & & \\
\hline or somebody stops me & 41.4 & 58.6 \\
\hline I have no supervisors or trainers & 96.6 & 3.4 \\
\hline
\end{tabular}

\section{Discussion}

\section{Perceived benefits}

The present study identified the perceived benefits of exercise by elderly; exercise makes the body physically and mentally healthy. Exercise helps to reduce stress, provide good sleep at night and give a better look. The finding of present study was supported by a focus group study done by Hutton Letaland Sin M , Logerfo J, Belza BA, Cunningham $\mathrm{S}$. They identified the perceived benefits of exercise by elderly were improvements in mobility, general health, posture, weight control, and pain reduction which makes body physically healthy, improves physical health and increase mental alertness, brings good emotional feeling and stimulation, provides greater relaxation and improved sleep.

\section{Perceived barriers}

The present study findings identified the main barriers perceived by the elderly were pain on body, and has no long term benefits, lack of information regarding exercise, difficulty to perform in old age due to loss of strength in old age and considered exercise as a tough task. The other barriers were lack of interest, and self-conscious about the body while performing exercise. A focus group study done by Hutton $L$ et al and $\operatorname{Sin} M$, Logerfo J, Belza BA, Cunningham $S$ identified the perceived barriers as becoming self-conscious about their body, pain and pathology, poor health, advancing age and lack of information regarding exercise which was similar to the findings of present study. The other barriers which were not identified by the present study were medical reasons or hospital admissions, fear of adverse effects and pace for performing exercise in a group.

\section{Perceived self-efficacy}

In the present study most of the subjects felt confident, 
self-worthy and fit to perform exercise. M ajority perceived that they can manage the time schedule and participate in exercise.

The findings of focus group studies done by Hutton L etal and $\operatorname{Sin} \mathrm{M}$, Logerfo J, Belza BA, Cunningham S were the elderly perceived that they had lack of self-confidence and lack of self-belief which contradicts the present study findings.

\section{Activity related effect}

In the present study majority felt that performing exercise will make them happy, energetic and daily life enjoyable. All the participants felt that exercise will not make them sad.

The findings of present study were supported by a focus group study done by $\operatorname{Sin}$ M, Logerfo J, Belza BA, Cunningham S. They identified that majority of elderly perceived that exercise makes them diligent.

\section{Interpersonal influences}

The present study findings shows that majority of the participants were motivated by the care givers to perform exercise, influenced and encouraged by the friends. $M$ ajority were not aware of the benefits of exercise from media. Most of them felt that they don't want any company to perform exercise.

The present study findings were supported by a focus group study conducted by Hutton $L$ et al. They identified

\section{References:}

1. WHO global health and ageing [Internet] 2011. Available from : http: //www.who.int/ageing/publications/global_health/en/index.html.

2. India's aging population [internet] $2012 \bar{M}$ ar 13. Available from: http://www.prb.org/Reports/2012/india-older-population.aspx.

3. Pender's health promotion model [Internet] 2012. Available from: http://nursingplanet.com/health_promotion_model.html

4. Nang F. Pender's Health Promotion M odel [Internet] 2012. Available from: http://www.slideshare.net/CharmaineFaye/penders-healthpromotion

5. Petursdottir U, Arnadottir SA, Halldorsdottir S. Facilitators and Barriers to Exercising Among People withOsteoarthritis: A Phenomenological Study. Physical Therapy. 2010; 90 (7): 1014-1025.

6. Hutton $L$ etal. The perceptions of physical activity in an Elderly population at risk of falling: a focus group study. Physiotherapy]. 2009; 37(2): 85-92.

7. Sin M, Logerfo J, Belza BA, Cunningham S. Factors influencing exercise participation and quality of life among elderly Korean Americans. J of Cultural Diversity. 2004; 11(4): 139-145.

8. Jacqueline A. McQuigg W, Prohaska TR. Factors Influencing Participation of African American Elders in Exercise Behavior. Public Health Nursing. 2001; 18 (3): 194-203. motivation was perceived as a promoter for performing exercise, but the study found that elderly need company of friends and like to perform in group which was contradicting the present study findings.

\section{Situational influences}

The present study identified that lack of facilities, lack of supervisor or trainer, and feelings that somebody or something stops when they start doing exercise as the situational barriers.

The findings of the focus group study by Hutton $L$ et al support the present study findings as they identified the perceived situational promoters were sociable and enjoyable atmosphere and a proper instructor.

\section{Conclusion}

The study explored various perceptions of elderly on performing exercise. Based on the factors health professionals and caregivers can plan and modify the interventions. Community health nurses can teach family members and elderly about the exercise and explain its benefits and encourage incorporating in daily activity plan for institutionalized geriatric population. This will help the nurse to promote independence and sense of achievement among the elderly and these measures help the elderly in preserving and promoting function rather than contributing to a decline in their status. 